\title{
Use of WhatsApp to monitor proper brace application and compliance in a case of clubfoot: a feasibility report
}

\section{Ganesh Singh Dharmshaktu*}

Department of Orthopaedics, Government Medical College, Haldwani, Uttarakhand, India

Received: 24 June 2018

Accepted: 30 July 2018

\section{*Correspondence:}

Dr. Ganesh Singh Dharmshaktu,

E-mail: drganeshortho@gmail.com

Copyright: () the author(s), publisher and licensee Medip Academy. This is an open-access article distributed under the terms of the Creative Commons Attribution Non-Commercial License, which permits unrestricted non-commercial use, distribution, and reproduction in any medium, provided the original work is properly cited.

\begin{abstract}
Internet provides immense potential to learn, indulge and implement several aspects of knowledge related activities for professionals and general enthusiasts alike. Emergence of social medial platforms, in the current scenario, has exponentially increased the reach of the data and thus its potential impact. WhatsApp is one of the leading media platforms to share views and news to a connected group and is widely used for its simple interface and ease of application. Its varied usage has benefitted biomedical and healthcare settings as well. We hereby describe feasibility of its use in home monitoring of brace application in a case of clubfoot by collaborating with parents. This turns out to be an exciting tool for this purpose in selected cases.
\end{abstract}

Keywords: WhatsAPP, Record keeping, Compliance, Monitoring, Clubfoot, Bracing, Smartphone, Mobile application

\section{INTRODUCTION}

Internet has affected our life in enormous manner and has impacted the world with its power to be of some use to everyone. It has provided us with wealth of knowledge in every arena of human endeavor including the healthcare and medical field. Any information regarding the medical fact or claim can be confirmed through the internet for its validity or the internet can be harnessed for continuous professional development through online learning materials and courses. ${ }^{1,2}$ The emergence of newer technological breakthroughs like artificial intelligence (AI) are bound to transform healthcare field in coming future and will not only affect personalized care but also affect how well a manuscript is kept plagiarism free among many other things. ${ }^{3}$ The WhatsApp is a preferred platform to share the views and other materials through internet and is simple, effective and gaining a huge user base by each passing year. It has been used for various purposes by healthcare researchers from patient interaction to record keeping. Its use can also be extended to simple day-to-day practice like reducing patient visits by providing effective methods of distant surveillances.

\section{CASE REPORT}

A 4 months old male child was brought to us with congenital bilateral foot deformity and was diagnosed with bilateral idiopathic clubfoot. He was managed by corrective weekly casting as per the Ponseti protocol that is standard practice currently. The method requires serial manipulation and casting in a specific sequence to achieve corrected cavus, varus and adduction elements of the deformity. Thee equinus, that is last deformity to be corrected, was managed by percutaneous Achilles tendon tenotomy followed by final plaster. After 3 weeks of final plaster, the plaster was removed to prescribe foot abduction braces (FAB) with proper demonstration of its application and protocol well explained to parents. The compliance and correctness of application of braces is monitored in initial months by follow up. The regular follow up visits are required to check fitness of brace for 
any wear, possibility of change and proper compliance. In order to decrease the number of follow up visits to reduce financial and man-hour loss a feasibility study was done on one case after proper informed consent of parents and after ensuring their capability to capture good images and send it through WhatsApp. Proper demonstration of technique and angles of images to be taken were explained with one satisfactory demonstration given by parents themselves. Thrice a week fresh images of brace applied with attention to overall fitting and status of heel well seated inside brace when observed through the inspection hole of the brace was ensured. The method helped reduce six number of visits in two years and once initial improper fit on WhatsApp image the parents were called and reinstructed followed by uneventful follow up later on (Figure 1).

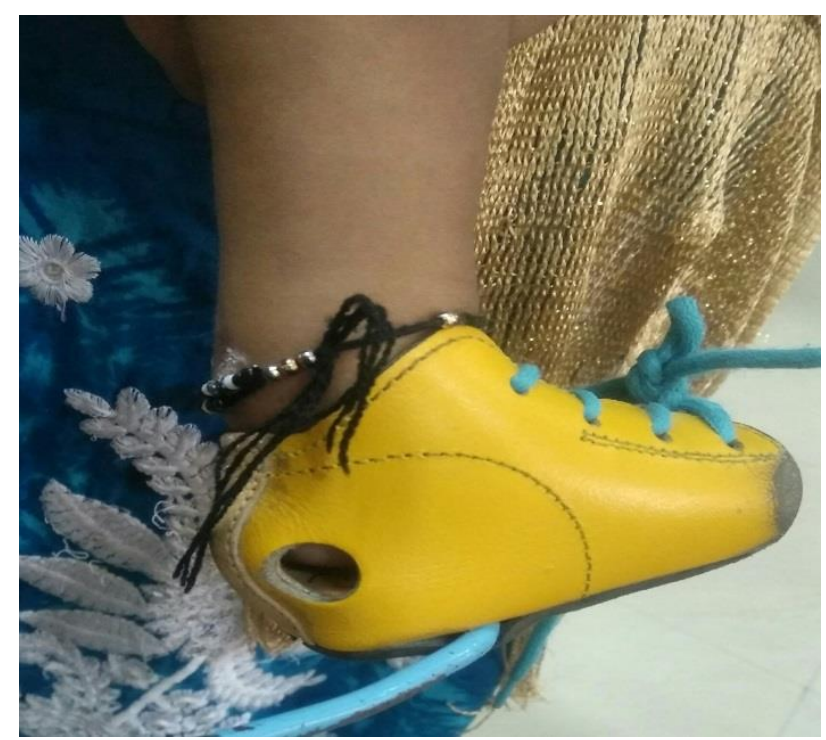

Figure 1: The WhatsApp image showing improper application and fitting of clubfoot brace by parents as the heel of the foot is not fitted well inside brace. The parents were called for visit for retraining and then proper application was checked regularly on WhatsApp.

\section{DISCUSSION}

WhatsApp has been used extensively in healthcare to communicate between provider groups or between patient and doctor or for learning purposes. ${ }^{4}$ It is simple, relatively inexpensive method of communication with text, video or online chats. It is relatively safe also owing to encryption across systems. However, there is need for better patient confidentiality, consent, data protection and security provisions along with many disadvantages. ${ }^{5}$ Opinion regarding fracture pattern has been shown to be facilitated by mobile apps in a study on orthopedics. ${ }^{6}$ Its use in monitoring is still underreported. Home management of pin tract care has shown promising results when monitored by WhatsApp in one previous report. ${ }^{7}$ The data is limited to few reports and small scale studies and information regarding its efficacy and long term results require high quality research. ${ }^{8}$ The technique in our case can be useful in selected cases only with dedicated, educated and tech savvy parents. There is limitation that even after proper utmost care, only one to one interaction is good in these settings as sharing data on groups even intra-disciplinary may risk data breach. All the aspects of proper data handling proficiency should be ensured before initiating this method in routine manner.

Funding: No funding sources

Conflict of interest: None declared

Ethical approval: Not required

\section{REFERENCES}

1. Dharmshaktu GS, Dar JA, Singh B, Bhandari SS, Singh P. Online validity and accuracy of references within drug promotion literature in orthopaedics out-patient department. Int $\mathbf{J}$ Orthop Sci. 2017;3(4):271-3.

2. Dharmshaktu GS, Pangtey T. Strenthening clinical research education in India:The massive open online course. Digit Med. 2016;2:127-8.

3. Dharmshaktu GS. Tackling author plagiarism with emma identity. J Indian Orthod Sci. 2017;51:298-9.

4. WhatsAPP. WhatsApp status. Available at: http://blog.whatsapp.cpm/webcite. Accessed on 3 May 2018.

5. Mars M. Scott RE. WhatsApp in clinical practice:A literature review. In The Promise of New Technologies in an Age of New Health Challenges. 2016 A.J. Maeder et al(Eds) IOS Press, Netherlands. 2016.

6. Giordano V, Koch H, Mendes C, Bergamin A, Souza FS, Amaral NP. WhatsApp messenger is useful and reproducible in the assessment of tibial plateau fractures:inter- and intra-observer agreement study. Int J Med Inform. 2015;84(2):141-8.

7. Dharmshaktu GS, Khan I. 'WhatsApp' as an adjunct to home based pin tract care:a case report. Int J Res Med Sci. 2014;2:1746-7.

8. Giordano V, Koch H, Santos AG, Belangero WD, Pires RE, Labronici P. WhatsApp messenger as an adjunctive tool for telemedicine:An overview. Interact J Med Res. 2017;6(2):11.

Cite this article as: Dharmshaktu GS. Use of WhatsApp to monitor proper brace application and compliance in a case of clubfoot: a feasibility report. Int J Res Orthop 2018;4:808-9. 